\title{
Prevalence of domestic violence on pregnant women and maternal and neonatal outcomes in Bandar Abbas, Iran
}

\author{
Abdol Azim Nejatizade ${ }^{1}$, Nasibeh Roozbeh ${ }^{2}$, Asiyeh Pormehr Yabandeh ${ }^{3}$, Fatemeh Dabiri ${ }^{3}$, Azita Kamjoo ${ }^{3}$, \\ Arefeh $\mathrm{Shahi}^{3}$
}

${ }^{1}$ MD, Ph.D., Associate Professor, Human Molecular Genetic, Molecular Medicine Research Center, Hormozgan University of Medical Sciences, Bandar Abbas, Iran

${ }^{2}$ Ph.D., Assistant Professor, Mother and Child Welfare Research Center, Hormozgan University of Medical Sciences, Bandar Abbas, Iran

${ }^{3}$ M.Sc., Instructor of Obstetrics Department, Mother and Child Welfare Research Center, Hormozgan University of Medical Sciences, Bandar Abbas, Iran

\section{Type of article: Original}

\begin{abstract}
Background: Pregnancy by itself, imposes great physical and psychological pressures on a person and consequently, coupled with other stressors such as violence, can have adverse effects on the fetus and mother. Objective: To assess the prevalence of domestic violence in pregnant women and maternal and infants' outcomes.

Methods: This is a descriptive study using a questionnaire. Data were collected from 725 women who delivered their babies at Shariati Hospital in Bandar Abbas in the summer and autumn of 2013. The questionnaire consisted of four parts: demographic characteristics, factors affecting violence, areas of violence (physical, emotional, sexual) and maternal and fetal outcomes. Data analysis was performed by SPSS 18 using descriptive statistics, ttest, Chi-square, and logistic regression.

Results: The prevalence of physical, sexual and psychological violence were $6.5,14.8$ and $9.9 \%$, respectively. The variables of age, duration of marriage, previous marriage experience and the husband's addiction, had a significant relationship with applying physical violence of the husband. There was significant correlation between physical violence and maternal outcomes $(\mathrm{p}<0.000)$. There was a statistically significant association between physical violence and low birth weight and growth delay in the uterus $(\mathrm{p}=0.033)$.

Conclusion: Due to the relatively high violence in pregnancy, and its impact on maternal and neonatal outcomes, it is suggested that violence screening programs in the health system and educating health professionals and women at risk and also the implementation of programs to protect these women, can be effective in reducing the cycle of violence and its negative consequences.
\end{abstract}

Keywords: Domestic violence, Women, Maternal outcome, Neonatal outcome

\section{Introduction}

Violence is a hidden epidemic, and continual in the lives of the affected women whose health and well-being is at risk. For this reason, the issue of women in health and social issues is important, and is known as a major public health problem (1-3). According to the World Health Organization definition, violence refers to any act against women that causes physical, psychological harm or suffering or sexual violence and lack of freedom and authority (2). According to a World Bank report, rape and domestic violence is more prevalent than diseases such as breast and cervical cancer and accident causes loss of 44-15 year-old women's health. (4). Therefore, around $40-50 \%$ of women at some point in their lives experience domestic violence. As a result, their physical and mental health is affected, and sometimes leads to suicide (5) Violence may occur at any time during a woman's life including their

\section{Corresponding author:}

Asiyeh Pormehr Yabandeh, Hormozgan University of Medical Sciences, Bandar Abbas, Iran.

Tel: +98.7633667904, Fax: +98.76-33670724, Email: Asipormehr@yahoo.com

Received: November 01, 2015, Accepted: June 27, 2017, Published: August 2017

iThenticate screening: June 20, 2017, English editing: July 28, 2017, Quality control: August 02, 2017

(C) 2017 The Authors. This is an open access article under the terms of the Creative Commons Attribution-NonCommercialNoDerivs License, which permits use and distribution in any medium, provided the original work is properly cited, the use is non-commercial and no modifications or adaptations are made. 
pregnancy. Pregnancy by itself imposes a great physical and psychological pressure on the person and naturally, coupled with other stressors such as violence, can have adverse effects on the fetus and the mother, and the effects can cause the increase of maternal and infant mortality (6). Among the factors involved in violence during pregnancy, factors such as low educational level, smoking and drug abuse, unwanted pregnancy, low income, unemployment, less than 5 years of marriage, forced marriage, first pregnancy, age and physical and mental health of the couple are to be noted (2-4). The increase of the vulnerability of women, the increase of economic pressure and decrease in sexual intercourse in pregnancy are mentioned (1). Factors, such as the transition to the parenthood role, result in impaired balance and harmony of couples, and causes a shift in the pattern of their previous relationship (2). The prevalence of domestic violence imposed during pregnancy has been reported as $1-30 \%$ in various studies. The degree of violence in Iranian pregnant women has been reported by more than $60 \%$ in conducted studies $(5,7)$. Violence during pregnancy leads to premature labor, low birth weight, abortion, hypertension, chorioamnionitis, an increased rate of caesarean, stillbirth, urinary tract infection, chronic pelvic infection, anemia and increasing depression during pregnancy and after childbirth (2, 8-10). .Also, cases of repeated violence and lack of delay for prenatal care can be noted (1). Violence includes three areas of physical, psychological and sexual, but most studies have focused on the area of health in pregnancy. Given that study in all three areas is insufficient, and since no study in this area has been done in Hormozgan province, research on violence in pregnancy in Bandar Abbas was considered as steps to provide approaches for prevention and timely measures in this area.

\section{Material and Methods}

This study was conducted in Shariati Hospital (a referral and educational Hospital) in Bandar Abbas in 2013. Criteria of inclusion for the study were gestational age of above 20 weeks, Iranian nationality, the absence of known physical and mental illness. The sample number for this study was determined as 725 (13), and simple random sampling method was used. To collect the data, the researcher made questionnaire were designed by reading scientific resources and validated by expert views. The violence questionnaire was validated using the method of determining the validity of the content (Content Validity). To this purpose, the viewpoints of 10 faculty members of Hormozgan University of Medical Sciences (gynecologists and obstetricians, midwives and nurses) were used. To test the reliability of the tools, a pre-test study was conducted and use of Cronbach's alpha coefficient was determined. That is, after interviewing 30 individuals on similar subjects under the study and completing the questionnaire, Cronbach's alpha was calculated and reliability of the questionnaire was 0.85 and contains 46 questions. The questionnaire contained four parts; The first part had 19 questions about demographic characteristics; the second part, 4 questions about the factors affecting the violence; third part, 12 questions on violence (physical, emotional and sexual) in pregnancy and the fourth, 11 questions on pregnancy outcome (mother and fetus) the purpose of which was fetal, low birth weight, fetal death, Apgar score and other outcomes and the consequences of motherhood pertaining to abortion, preterm labor, premature rupture of membranes of placental abruption and other complications. The questions on violence are designed to have at least one positive answer to each question (physical, emotional or sexual), which is carried out by the husband during pregnancy. The domain of physical violence includes behavior such as hitting, beating, use of an implement to hit, etc. Sexual violence was evaluated with questions such as requests and acts for sexual intercourse and coercion against one's desire. In the area of emotional violence, questions were asked about the existence of such things as insults, humiliation, threats of separation and death. After obtaining the consent of the patient and ensuring the confidentiality of information, questionnaires were completed anonymously. We used descriptive statistics, t-test, Chi-square, and logistic regression for data analysis by SPSS version 18 (SPSS Inc., Chicago, Illinois, USA).

\section{Results}

The results showed that the average age of women participating in the study was 24.6 years. The average age of their spouses was $30.73 \pm 6.56$ years. The average duration of marriage was 4.81 . The majority of the women participating in the study had experienced their first pregnancy $(53.8 \%)$. Most people attending the study were urban dwellers $(58.9 \%)$. In total, $93.2 \%$ of women were married with the consent of their own choice. Only $2.2 \%$ of women and $7 \%$ of their partners had a history of a previous marriage. The education level of women was generally low; $33.7 \%$ had primary education, and more than $90 \%$ of the women in the study were housewives. Most women said that their husbands do not have any drug or alcohol addiction $(86.1 \%)$. In this study, the prevalence of physical, sexual and psychological violence was noted $6.5 \%, 14.8 \%$ and $9.9 \%$ respectively. By means of logistic regression test (Table 1), it was shown that the variables of age, addiction of husband, marriage duration, marriage status of the spouse and women's medical record of chronic disease had a significant relationship with domestic violence. Between planned or unplanned pregnancies and physical violence, no significant relationship was found. Also, no 
significant relationship between women's education and physical violence was found, while there was a significant correlation between men's education and domestic violence $(\mathrm{p}=0.04, \mathrm{r}=0.75)$. It means that the more educated a man, the less domestic violence there is. Based on the findings of this study, it was indicated that there is a direct relationship between physical violence and maternal outcomes. This means that if more physical violence was committed against women during pregnancy, the maternal consequences would be greater $(p<0.000)$. Yet, no significant relationship between sexual and psychological violence and maternal outcomes was found. Also, there was statistically significant relationship between physical violence and low birth weight (LBW), which is of fetal outcomes $(\mathrm{p}=0.033)$. The results showed that there was a significant relationship between physical violence and LBW $(\mathrm{p}<0.000, r=0.164)$, but there was no statistically significant relationship between psychological and sexual violence with other variables related to fetal outcome.

Table 1. Logistic regression analysis results controlling the possible effects of demographic variables on domestic violence

\begin{tabular}{|l|l|l|l|l|}
\hline Independent variable & Scale & Beta coefficient & p-value & Odds ratio (OR) \\
\hline \multirow{4}{*}{ Age (years) } & $>20$ & -- & -- & 1 \\
\cline { 2 - 5 } & $20-25$ & -0.69 & 0.001 & 0.49 \\
\cline { 2 - 5 } & $<25$ & 0.91 & 0.022 & 2.5 \\
\hline \multirow{5}{*}{ Addiction of wife (Yes/No) } & Cigarettes & 2.09 & 0.039 & 8.16 \\
\cline { 2 - 5 } & Narcotics & 2.53 & 0.06 & 12.56 \\
\cline { 2 - 5 } & Other addictive substances & 3.19 & 0.001 & 24.28 \\
\cline { 2 - 5 } & Alcohol & -- & -- & 1 \\
\hline Duration of marriage (years) & $2-5$ & 2.15 & 0.011 & 8.66 \\
\cline { 2 - 5 } & $5-10$ & 1.01 & 0.162 & 2.76 \\
\cline { 2 - 5 } & $10-15$ & 0.17 & 0.819 & 0.837 \\
\cline { 2 - 5 } & $<15$ & -- & -- & 1 \\
\hline \multirow{5}{*}{ Husband's remarried status } & Yes & 2.27 & 0.027 & 9.55 \\
\cline { 2 - 6 } & No & -- & -- & 1 \\
\hline Women experiencing chronic illness & Yes & 0.818 & 0.097 & 2.26 \\
\cline { 2 - 5 } & No & -- & -- & 1 \\
\hline \multirow{2}{*}{ Husband's Education } & Below high school diploma & & 0.04 & 0.75 \\
\cline { 2 - 5 } & Above high school diploma & -- & -- & 1 \\
\hline
\end{tabular}

\section{Discussion}

The results of our study showed that the most common types of violence were respectively $14.8 \%$ of sexual violence, $9.9 \%$ psychological violence, and 5.6\% physical violence. In a study of Dolatian in 2009 entitled 'the prevalence of abuse during pregnancy' it concluded that physical violence was the lowest form of violence in number, (8) which is consistent with our results. Also, in a study that was conducted in Ahvaz, physical violence was less in number in comparison to other forms of violence which is consistent with our study (11). Wives' sexual harassment in our study was 14.8\% which is consistent with Salehi's study in Shahrekord (13.8\%) (5). In a study in China, none of the pregnant women had experienced physical violence during pregnancy (12), while other studies have reported physical violence with more statistics $(1,5)$. The existing difference between the prevalence of violence among women with different frequencies has been reported that this difference may be due to methodology, sampling and cultural differences and the willingness of respondents to disclose experiences of domestic violence during pregnancy as part of their private lives. It seems that men's fear of maternal and fetal risks for physical violence is perhaps the reason for these differences. In our research, women whose husbands had not consumed alcohol or drugs, experienced less violence, and that has been consistent with the results of Salehi and Hassanzadeh $(5,11)$. Addicts experience the consequences of emotional, social, cultural and special spiritual experience; considering emotionally low self-esteem, lack of control, reduced frustration tolerance, emotional instability, anger, and anxiety and depression experience, and these factors are the causes (12). Experts consider violence against women and its increase is due to economic pressures, mental health problems caused by alcohol and drugs in a way that the findings of a study in 2001 on 439 women beaten by their husbands, showed that $40 \%$ of women had married drug addicts (13). In our study, women in the age group below 20 years experienced physical violence 2.5 times that of the age group over 25 years. In a study in Australia, a significant relationship between age and incidence of violence in pregnant women was reported (14). Also, our study results are consistent with research conducted by Dolatian (8). Being inexperienced at a younger age results in lack of ability to solve problems the 
outcome would be maladaptive behavior in family relationships. In our research, with the increase of men's education, the rate of domestic violence is lower. In the study of Saberian, experience of financial, verbal and physical violence in women with husbands with lower education than high school diploma was higher (15). In this study, women who have been married less than 2 years are subject to physical and sexual violence more than those who have been married more than 15 years. In this regard, Salehi and Mehralian, in their study, reported that domestic violence is reduced with increasing duration of marriage (5). Also, Dolatian et al., stated that duration of marriage less than 5 years was associated with a higher incidence of violence (8). Our study showed that the lower men's education, the greater prevalence of domestic violence there is. Men's education can affect the family's socioeconomic status and the results show that women who are unhappy with their economic and financial situation, more than twice as those who are satisfied with their financial situation, are subject to sexual violence by their husbands. The study of Derakhshanpour and his colleagues also indicated that violence against women was associated with a lack of financial consent (16). While in a study by Taherkhani, there was no connection between the economic situation and domestic violence. They stated that the difference in data collection tools can be the reason for the difference with other studies (4). Dolatian has also shown that more violence was witnessed in women with an unemployed husband (8). In the current study, women who have been subject to physical violence, preterm labor chance is increased, which is consistent with the results of the Bagherzade research (17). Although several medical and environmental factors have been linked with preterm birth and low birth weight babies, according to the results of some studies, maltreatment of mothers during pregnancy can also, through different mechanisms, cause the occurrence of the above-mentioned disorders. Physical and sexual trauma through the release of stress hormones can lead to premature delivery and low birth weight (18). With the pregnant mother's body and fetus experiencing stress, the hypothalamus-pituitary-adrenal axis channel containing neuroendocrine start simultaneously producing cortisol in the mother and fetus (6). Cortisol, with several mechanisms such as reducing maternal and fetal immune system, can increase the amount of infection in their children, preterm birth and fetal birth weight. On the other hand, the physical and psychological symptoms, anxiety, inadequate care and lack of social support, which sometimes occurs following the outbreak of violence, may affect attitudes of women, tolerance and the influence her attention to hygiene and health. As a result, the possibility of actions that endanger the health of the woman and her fetus, such as smoking, alcohol, lack of referring to health centers to receive prenatal care increases. Thus, in a reverse cycle, the process of pregnancy, childbirth and postpartum would go under degrading $(19,20)$. In our study, there was a statistically significant association between physical violence during pregnancy and LBW, and it is consistent with Faramarzy, Dolatian and Nojoomy research $(8,12,18)$. Also, the study of Bahery showed that there is a relationship between verbal and psychological violence during pregnancy and the incidence of LBW (21). Pregnancy by itself, imposes many physical and psychological pressures on mothers and, of course, coupled with other stressors such as violence, can cause adverse effects on the fetus and the mother. Mothers who are subject to domestic violence are less likely to take care of themselves to receive prenatal care and nutritional supplementation in pregnancy which can cause low birth weight and preterm labor. Preterm labor is the main reason of infants' morbidity and mortality and the main cause of undesirable consequences of pregnancy (22) Due to adverse outcome of domestic violence, screening of pregnant women against violence is necessary.

\section{Limitations and strength of the study}

Our study was of cross-sectional type, and data were extracted from hospital wards. The limitation to access the research journals and articles is among other restrictions of this study. One of the strengths of our study is the subject of study. Given that no study has been conducted in the province of Hormozgan to identify the prevalence of domestic violence against women and maternal and neonatal outcomes, identifying the frequency of prevalence of domestic violence in pregnancy factors and consequences associated with it, in addition to helping to find measures to prevent this issue, can reduce its due consequences.

\section{Conclusions}

Due to the sensitive nature of the gestation period and its importance in the future health of the mother, screening for violence during counseling before pregnancy and prenatal care is recommended. The growing awareness regarding violence and its complications in pregnancy, legal protection for victims' subject to violence and complications in pregnancy, improving the working conditions of women in society, improving the knowledge of adolescents and youth in regard to domestic violence and its complications and providing life-skills training in the form of training programs for these groups, will reduce the incidence of domestic violence. It is suggested that a case-control study be conducted to control the confounders in this field and to collect data from other research sources such as health centers and institutes to be used. 


\section{Acknowledgments:}

The authors express their gratitude to the colleagues at Hormozgan University of Medical Sciences for their assistance and all of those who helped conduct this study.

\section{Conflict of Interest:}

There is no conflict of interest to be declared.

Authors' contributions:

All authors contributed to this project and article equally. All authors read and approved the final manuscript.

\section{References:}

1) Hesami K, Dolatian M, Shams J, Majd H. Domestic Violence Before and during Pregnancy among Pregnant Women. IJN. 2010; 23 (63):51-59.

2) Behnam H, Mogaddam HV, Soltanifar A. A survey on the intensity and frequency of domestic violence during pregnancy.HMSJ.2007; 14, (2):70-76.

3) Babu BV, Kar SK.Domestice violence against women in estern india:a population -based study on prevalence and related issues.BMC Public Health.2009;9(129):1-15. PMID: 19426515

4) Taherkhani S, Mir Mohammad Ali M, Kazemnejad A, Arbabi M, Amel Valizadeh M. Prevalence of domestic violence against women and its relationship with the couple's profile.Journal of Legal Medicine .2008; 15( 2):123-129.

5) Salehi S, MehrAlian H A. Prevalence of domestic violence among pregnant women who refered to health clinice of Shahrecord2002. J Shahrekord Univ Med Sci. 2005; 8(2):72-77.

6) Shamsi M, Bayati A. Frequency and severity of domestic violence in pregnant women. J Gorgan Uni Med Sci. 2011; 13 (4):67-75.

7) Ali Kamali M, Rahimi Kian F, Mir Mohamad A, Mehran A, Shafiei E. Comparison of domestic violence and its related factors in pregnant women in both urban and rural population in Zarand city, 2014. J Clin Nurs Midwifery.2015; 4(2):69-78.

8) Dolatian M, Gharache M, Ahmadi M, Shams J, Alavi Majd H. Relationship between partner abuse during pregnancy and pregnancy outcomes. Hmj. 2010; 13 (4):261-269.

9) Shamu S, Abrahams N ,Temmerman M , Musekiwa A. Zarowsky C.A systematic Review Of African Studies On Intimate Partner Violence Against Pregnant women: Prevalence and Risk Factors.Plos One.March 2011 ;6(3):1-9. DOI: http://dx.doi.org/10.1371/journal.pone.0017591.

10) Abdollahi F, Abhari FR, Delavar MA, Charati JY. Physical violence against pregnant women by an intimate partner, and adverse pregnancy outcomes in Mazandaran Province, Iran. Journal of Family \& Community Medicine. 2015; 22(1):13-18. doi:10.4103/2230-8229.149577.

11) Hassan Zadeh S.Noohjah $S$ Haghighizadeh MH.Prevalence of domestic violence and related factors in pregnant women referring to health centers - Care of Ahvaz in 2009 .Journal - Research Jnta Shapyr.2010 ;2(3):104-110.

12) Nojomi, Agaee, Eslami. Physical violence during pregnancy and maternal and neonatal outcome. Journal of payesh.2001; 1(2):43-48.

13) Bodag Abady M .Pregnancy outcomes in victims who reffered to Mobini hospital of Sabzevar. HM J.2006; 12(3):41-46.

14) Meuleners LB.Lee AH,Janssen PA,Fraser ML.Maternal and foetal outcomes among pregnant women hospitalized due to interpersonal violence :A population based study in western Australia,2002-2008,BMC Pregnancy and Childbirth .2011;11(70).223-238. PMID: 21989086

15) Saberian M, Atash Nafas E, Behnam B. Prevalence of domestic violence in women referred to the heath care centers in Semnan (2003). koomesh. 2005; 6 (2):115-122.

16) Derakhshanpour F, Mahboobi HR, Keshavarzi S. Prevalence of domestic violence against women. J Gorgan Uni Med Sci. 2014; 16 (1):126-131.

17) Bagherzadeh R, Keshavarz T, Sharif F, Dehbashi S, Tabatabaei H. Relationship between Domestic Violence during pregnancy and Complications of Pregnancy, type of delivery and birth weight on delivered women in hospital affiliated to Shiraz university of Medical Sciences. Horizon Med Sci. 2008; 13 (4):51 58.

18) Faramarzi M, Esmaelzadeh S, Mosavi S. Prevalence, maternal complications and birth outcome of physical, sexual and emotional domestic violence during pregnancy. Acta Medica Iranica. 2005; 43(2):11522 . 
19) Shayeghian Z, Rasolzadeh Tabatabaey S, Seddighi looye E. Effect of Maternal Anxiety during Third Trimester of Pregnancy Outcomes and Infants' Mental Health . Hayat. 2009; 14 (4 and 3):57-65.

20) Van Dijk AE, Van Eijsden M, Stronks K, Gemke RJ, Vrijkotte TG. Cardio-metabolic risk In 5-year-old children prenatally exposed to maternal psychosocial stress: the ABCD study. BMC Public Health. 2010; 10(1):251. Doi: 10.1186/1471-2458-10-251.

21) Baheri B, Ziai M, Zeighami M, Zeighami Sh. Frequency of Domestic Violence in Women with Adverse Pregnancy Outcomes (Karaj 2007-2008). Scientific Journal of Hamadan Nursing \& Midwifery Faculty. 2012; 20 (1):31-41.

22) Roozbeh N, Moradi S, Soltani S, Zolfizadeh F, Hasani MT, Yabandeh AP. Factors associated with preterm labor in Hormozgan province in 2013. Electronic Physician. 2016; 8(9):2918-2923. Doi: 10.19082/2918. 